\title{
Computer History on the Move
}

\author{
Graham Farr, Barbara Ainsworth, Chris Avram and Judy Sheard \\ Monash Museum of Computing History, Faculty of I.T., Monash University, \\ 900 Dandenong Road, Caulfield East, Victoria 3145, \\ Australia \\ +6139905 4000 \\ \{Graham.Farr, Barbara.Ainsworth, Chris.Avram, Judy.Sheard\}@monash.edu
}

\begin{abstract}
Computer history tours are a new way to educate people about our discipline and its history. We describe the introduction of such tours and their use in curriculum enrichment, outreach, and academic community-building. These tours give historical and social context to the development of topics in the curriculum, and demonstrate to students the universality of some of the principles they learn. The city of Melbourne, Australia, serves as an illustration, but computer history tours can be run in many cities of various sizes, and we give advice on how to do this.
\end{abstract}

\section{Keywords}

Computer Science education; outreach; computer history; computer museum; computer tour.

\section{INTRODUCTION}

As a transformative discipline, information and communications technology (ICT) looks much more to the future than the past. But the field is now old enough that its past has much to teach about the evolution of technology and its relationship with society. ICT history shows the stages that led to its present, and gives clues about how it may yet develop.

Interest in the history of the field has increased markedly in recent years. It wasn't so long ago that most of the pioneers were still alive. As that first generation passes, the next generation becomes more conscious of the value of their heritage and the need to preserve it. Computer history collections have been developed in museums around the world (such as the Science Museum in London and Deutsches Museum in Munich), and whole museums devoted to computer history have been founded in several places. Physical computer history museums include: the Computer History Museum [7,27,40] in California; Heinz Nixdorf MuseumsForum [20,33] in Paderborn, Germany; The National Museum of Computing (TNMoC) [36] in the UK, and its neighbour, Bletchley Park [4]; the Nexon Computer Museum [31] in Jeju, Korea; and the Monash Museum of Computing History [28] in Melbourne, Australia. There are also virtual museums, such as the Virtual Museum of Computing [39] and the Information Processing Society of Japan (IPSJ) Computer Museum [22]. Through these endeavours, many important historical artefacts have been restored and displayed. Anniversaries of pioneers are celebrated, most notably with Alan

Permission to make digital or hard copies of part or all of this work for personal or classroom use is granted without fee provided that copies are not made or distributed for profit or commercial advantage and that copies bear this notice and the full citation on the first page. Copyrights for third-party components of this work must be honored. For all other uses, contact the Owner/Author.

Copyright is held by the owner/author(s).

SIGCSE '16, March 02-05, 2016, Memphis, TN, USA

ACM 978-1-4503-3685-7/16/03.

http://dx.doi.org/10.1145/2839509.2844575
Turing Year 2012 [8]. Conferences have been devoted to the field $[9,35]$.

The study of the history of computing is included in some university IT programs either as a separate course or woven into the curriculum of various courses [30]. For example, Draper et al. [11] describe a curriculum in which the history of computing is presented to students using technology as a framework, whereas Papadimitriou [32] proposes using a historical context to add interest to technical subjects. Impagliazzo \& Lee [21] and Zhang \& Howland [41] provide many reasons for studying the history of computing but also highlight the lack of resources for teaching this topic.

In this article we introduce a new way of presenting ICT history: computer history tours. In such a tour, people visit a series of sites related to the history of computing. The tour provides a framework for education on individual topics, with specific reference to experiences in the tour location (in our case, Melbourne) providing a context for presenting the overall development of the field. The tours serve several purposes: raising the profile of our discipline and awareness of its history; communicating the historical context of changes in technology and the computer industry; supplementing undergraduate education by illustrating and reinforcing concepts; using historical computers to show undergraduate students the universality of some of the principles they learn; providing enrichment opportunities for students; and academic and professional community-building. Other benefits include enhancing the international student experience, by providing a day of sightseeing that ties in with their education, and making contact with industry veterans who are able to provide new historical information.

Our tours attract a variety of participants including students, university staff, alumni, computer industry employees or veterans, computer hobbyists, and ordinary citizens looking for an unusual day out. We use a mix of walking and public transport. Among the places we visit are museums, sites (past and present) of notable companies and projects, and a cathedral. Artefacts studied include early calculators, an early commercial transistorbased computer, and the oldest surviving complete computer in the world. On the way, we see many historic buildings and enjoy breaks at cafés. Participants are encouraged to ask questions throughout the tour and this leads to many varied interesting technical and historical discussions.

Different kinds of computer history tours have been run in other places. Computer history museums typically offer tours of their collections. Some companies offer guided tours by vehicle of sites in Silicon Valley [1,3]. Alan Turing Birthday Walks have been held annually in Manchester since 2009 [17]. 
We conjecture that our tour is unique in that it is the first computer history tour anywhere that satisfies any one of the following: (a) takes place outside Silicon Valley; (b) is a free organised group tour; or (c) uses walking and public transport only. Our tour is not an event- or person-specific activity but rather makes an attempt to show the evolution of computing in different fields including academic, commercial and technical innovations. The tour covers many locations and differs from tours of one specific site such as a museum. The tour has evolved in response to our experiences and feedback from participants.

We also conjecture that computer history tours of this type could be run in many other places, and give advice on how to do this, with some potential examples.

\section{HISTORY OF THE TOUR}

The initial inspiration for our tours was a Mathematics Tour of Melbourne devised by Jill Vincent [38], which focuses on geometry in architecture and is aimed at secondary school mathematics students. Our tour differs in its subject matter and historical focus.

Our first Computer History Tour took place on 16 August 2008. It had 21 participants and took $6 \frac{1}{2}$ hours. Since then, we have conducted an average of just over two tours each year, making eighteen to date. The tour takes most of a day and covers many sites with connections to the earliest days of computing [12]. Each typically involves a group of 20-30 people travelling through inner Melbourne by a mix of walking and tram travel, stopping at about eight sites, sometimes for five minutes, sometimes for an hour. The tour is bookended by two museums: the Monash Museum of Computing History [28], and Melbourne Museum, the home of CSIRAC $[25,29]$, the oldest surviving complete computer in the world. (Melbourne Museum is part of Museum Victoria.) The tour on 1 December 2012 was part of the Alan Turing Year programme of events and dedicated to Turing's memory.

Within our university, the tour is promoted by our usual electronic channels to students and staff. Externally, in Melbourne, the tour has become known by media coverage, some public presentations, and word-of-mouth. In May 2009, just before our third and fourth tours, we were contacted by The Age newspaper in Melbourne. The resulting article [14] generated great public interest and a long waiting list of people for future tours. Other media coverage $[6,13,37]$ has added to the profile of the tours.

\section{DESCRIPTION OF TOUR}

Our tour begins at the Monash Museum of Computing History and ends at sites related to CSIRAC. Our website contains a guide to the tour schedule and background notes on the sites and points of discussion. The group is led by a team from the Faculty of IT, Monash University. Members of the team have specialist knowledge and they provide short commentaries as well as answer questions.

We follow a fixed route until reaching the south side of central Melbourne. The route through central Melbourne varies, as there is a number of sites scattered around this area and there is insufficient time to visit them all. After leaving the north side of central Melbourne, we finish the tour with sites connected with CSIRAC.

Here we review the "bookends" in more detail and browse some of the sites between them.

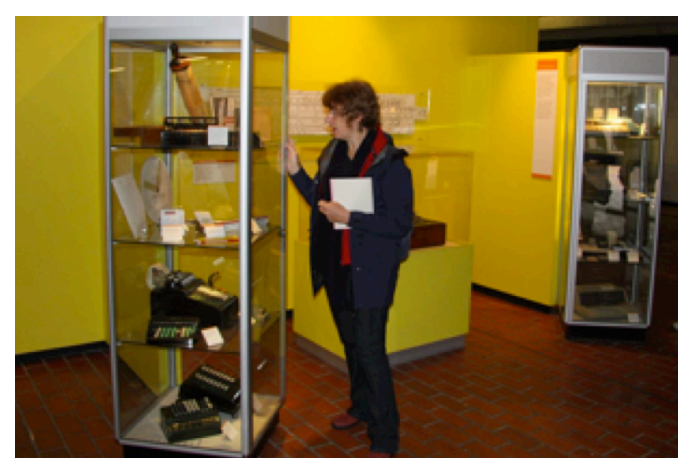

Figure 1: MMoCH calculator display

\subsection{Beginning of Tour : Monash Museum of Computer History}

The Monash Museum of Computing History (MMoCH) (Figure 1, 2) was established in the Faculty of Information Technology at the university's Caulfield campus in 2001. Its aims are "to provide a visual display of computing history as well as establish a reference collection demonstrating the use of computing technology at the university" [28].

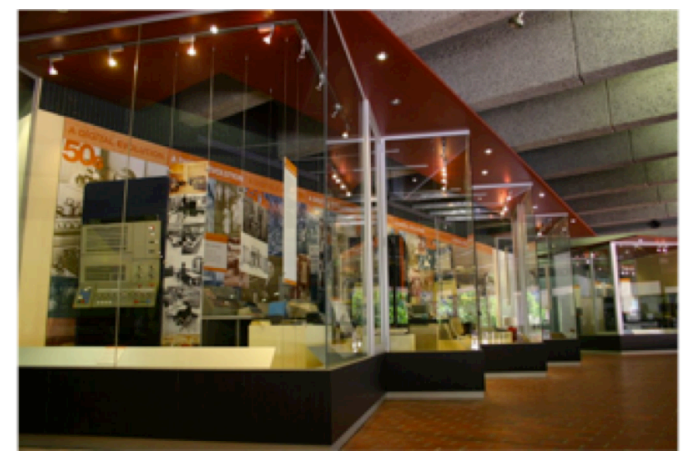

Figure 2: MMoCH, central section: 'A Digital Evolution' and (right) Ferranti Sirius display

The Museum is located in a foyer, outside a set of lecture theatres and classrooms, so its displays are frequently viewed by passing students. The display is divided into sections with an introduction to calculators (Figure 1), early computers and personal computers and a biographical component on key figures in Monash University's computing history. The central section of the display (Figure 2) presents the evolution of computer technology against a photographic backdrop illustrating the concurrent evolution of society. The Museum is a teaching resource and a focal point for the history of computing. We run a programme of public outreach including several visits each year by groups of school students. The Museum area is open to the public when the university is open and is free of charge.

The major item in the collection is Monash University's first computer, a Ferranti Sirius (1962), which was an early commercial transistor-based computer (Figure 3 ). The history of this machine is described by Ainsworth [2]. The display includes a short film which was produced in 1963 to explain the workings of a computer to office staff.

The tour starts in this Museum, though we usually gather at a nearby café first, which gets the day off to a good start socially. We explain the purpose and layout of the museum, and tell people about the Ferranti Sirius. 


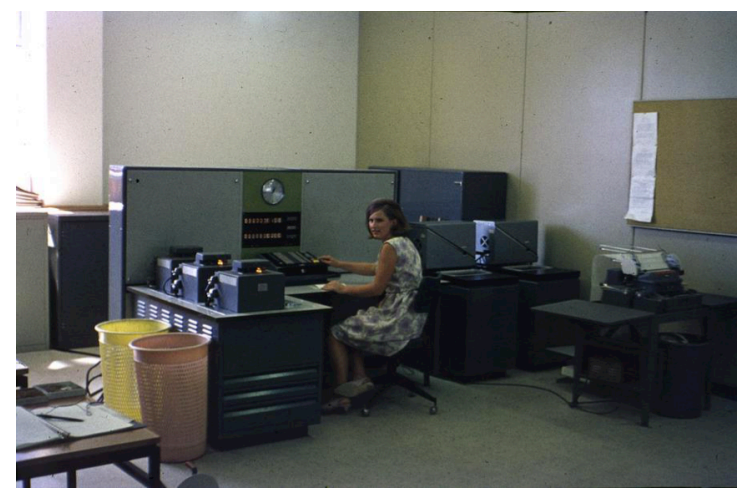

Figure 3: Ferranti Sirius at Monash University

(C) Trevor Hicks (Monash University)

\subsection{Middle of tour}

We then take a half-hour tram journey, which travels along two streets which were home to many computer companies in the early days of the industry. (We call this stretch the 'Silicon Mile', by analogy with the Golden Mile, a term used informally elsewhere in Melbourne.) We stop at an architecturally significant building, called 'Stanhill', which was the home of the Melbourne Computer Centre (Figure 4). This was a commercial computer bureau run by

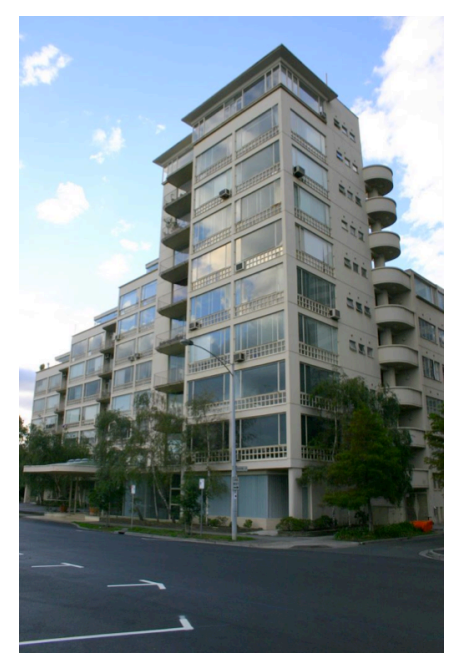

Figure 4: Stanhill the British firm, Ferranti Ltd. It provides an opportunity to discuss the nature of the computer industry, and the way computers were used in business, during the 1960s .

We then pass Monterey Apartments, where code-breaking was done during the Second World War, and continue up Silicon Mile to Melbourne Observatory (Figure 6). This observatory was established in 1863 (Figure 5) from the relocation and merger of Williamstown Observatory (est. 1853) and Flagstaff Observatory (est. 1858). It has been part of the Royal Botanic Gardens since 1997. There, we have lunch in a café, and take people to a particular window of the original observatory building so that they can see Melbourne's first Computer Room, which dates back to 1863. This was the workplace for the observatory's human computers, who were all unmarried women. This leads into a discussion of the evolution of the meaning of "computer", the naming conventions of computers (in particular, names ending in $-\mathrm{AC}$, for Automatic Computer, or Mark I), changes in the opportunities for women in employment, and the importance of computation in astronomy then and now.

After lunch, we pass Victoria Barracks, an Australian military installation, which used to house a Cray supercomputer used in cryptanalysis in the 1980s. We then visit St Paul's Cathedral, where we inspect a list of former Deans that contains the name of a great-great-grandson of Charles Babbage (Figure 7). Here we

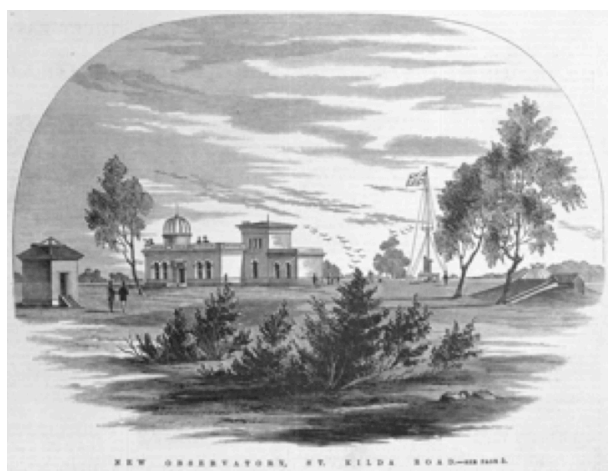

Figure 5: Melbourne Observatory, 1863

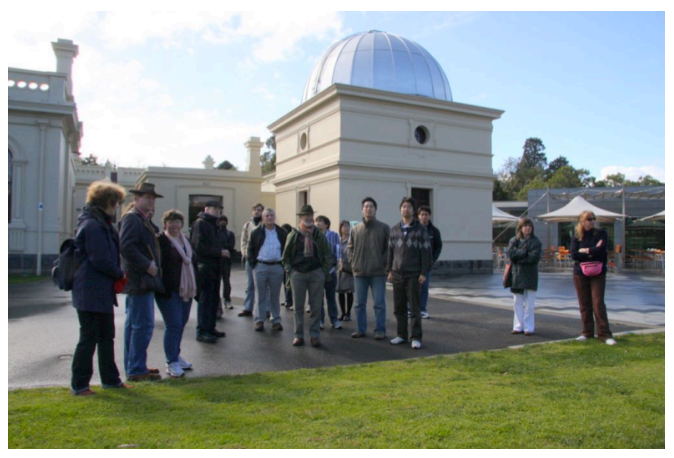

Figure 6: Computer History Tour visits Melbourne Observatory, August 2008

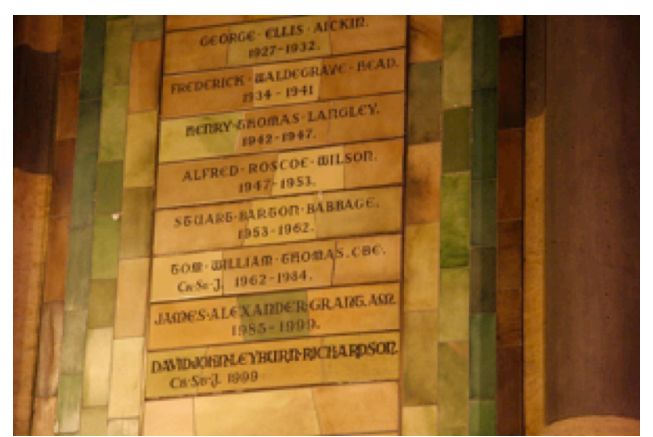

Figure 7: List of Deans of Melbourne, St Paul's Cathedral

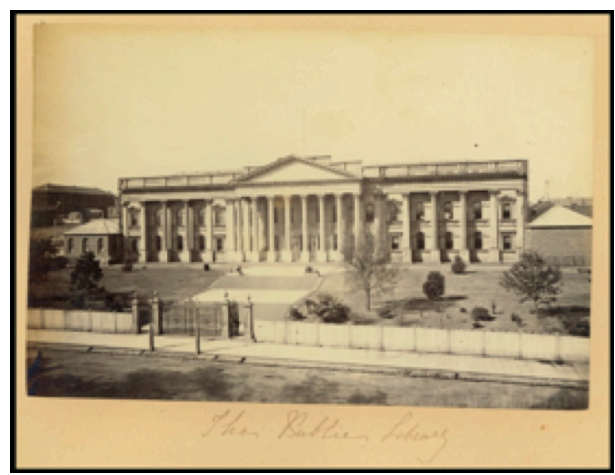

Figure 8: State Library of Victoria (then, the Public Library), late 19th century

take the opportunity to talk about Babbage's work and the origin of the concept of a computer.

Our routes through central Melbourne have varied. We may, for example, visit a plaque recording the first telegraph station in the 
southern hemisphere (1854), and Lonsdale Exchange where we can talk about the history of email and some network concepts such as packet switching and circuit switching. We may visit the State Library of Victoria (Figure 8), which introduced some innovative ways of using computers to improve information access, including one of Australia's first internet service providers, Vicnet [19]. We may visit some former sites of the Bureau of Meteorology, where computers were introduced in the 1960 s to handle their own "big data" deluge and from the 1990s contributed to the work of the Intergovernmental Panel on Climate Change [5].

\subsection{End of tour: CSIRAC}

CSIRAC was Australia's first computer, and is commonly agreed to have been the world's fourth (if we insist that the term "computer" requires stored-program architecture) $[25,29]$. It is

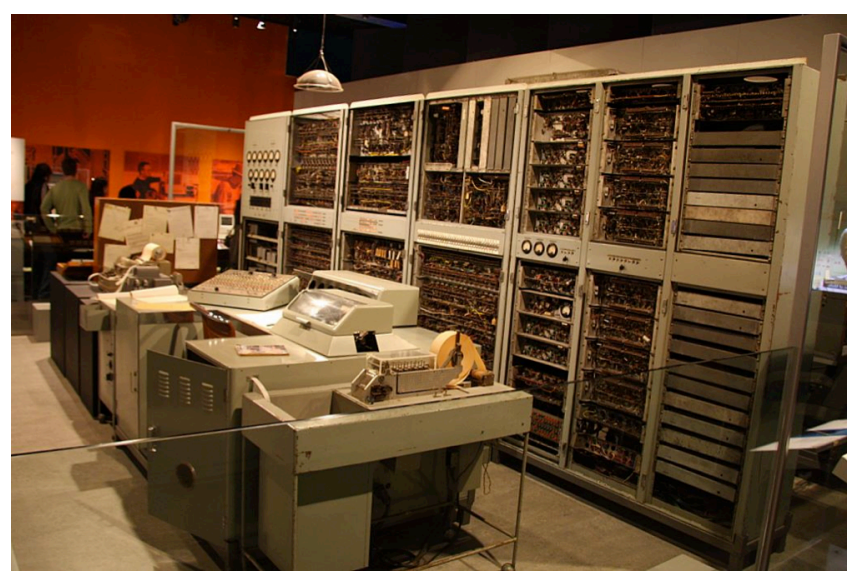

Figure 9: CSIRAC, in Melbourne Museum

the only complete surviving first-generation computer in the world, although it is no longer in working order. CSIRAC is also significant for the world's first computer music (1951). It is on permanent display at Melbourne Museum (Figure 9).

This computer was designed and built by Trevor Pearcey and Maston Beard in the Radiophysics Laboratory of the Council for Scientific and Industrial Research (CSIR) in Sydney from 1947. It was initially called CSIR Mark I and became operational in November 1949. In the same year, CSIR became the Commonwealth Scientific and Industrial Research Organisation (CSIRO).

CSIRO decided to devote more resources to rainmaking (unsuccessful) than computing (revolutionary) in the 1950s. CSIR Mark I was closed down and moved to the University of Melbourne in 1955. It was re-named CSIRAC (thereby switching between the two main computer-naming conventions of the day) and started work again in 1956. Among other achievements, it was used for Australia's first computer-based weather forecast in 1956. It remained at the University of Melbourne, operating very productively (with about $10 \%$ downtime), until it was retired in 1964. Fortunately, its custodians had the foresight, unusual at the time, to preserve it and placed the computer into the care of Museum Victoria.

In studying CSIRAC, we point out the various parts of the CPU, including the Arithmetic-Logic Unit, memory (mercury delay lines, and a later magnetic drum), and peripherals including paper tape devices, circular cathode ray displays (to show contents of memory registers), control switches, and a subroutine library (a collection of paper tape rolls in a box of pigeonholes). We outline how it worked, taking the opportunity to mention load-store architecture and the fetch-execute cycle. Students can see how fundamental and universal some of the principles they learn are, since they were present in these earliest computers.

During this last stage of the tour, we also visit the University of Melbourne to see the building that housed CSIRAC, from 1956 to 1964. The substantial gap between ground level, where we stand, and floor level above, indicates the large under-floor space which was an important source of cool air for temperature control.

While at the University of Melbourne, we pause outside the Richard Berry building, which housed Australia's first internet connection. This began operation on 23 June 1989. We discuss the differences between network layers (with the physical link to the US being from Sydney but the TCP/IP link from Melbourne). We note how internet speeds have changed: initially, the entire country was connected to the US by a $56 \mathrm{kbps}$ link, while today, most individuals would find that speed inadequate.

\section{HOW TO CREATE A COMPUTER HISTORY TOUR}

Melbourne is fortunate to have a number of important links to the early days of ICT. But, in fact, a tour like ours could be run in many other places around the world. To design a tour we recommend the following steps.

a) Investigate local museums. They may have displays of old computer and communications equipment.

b) Look for displays of old equipment at universities. It is not uncommon for Computer Science or Electrical Engineering departments to have such displays.

c) Every city had a first computer, at some stage. In some cases, this may be well known. In other cases, it may be identified with the help of computer industry veterans or the staff of large computer-using organisations such as universities, research laboratories, financial institutions, industrial plants, and of course computer companies.

d) Find out about historic astronomical and meteorological observatories in your area. These often employed human computers [18] and some had a computer room.

e) Find out about the introduction of telecommunications in your area, from local telecommunications companies or historical websites [15] and books [34]. Sites of early telegraph offices give an opportunity to draw historical parallels with the development and impact of the internet. Sites of old semaphore ("optical telegraph") stations [23] can serve a similar purpose, although fewer survive.

f) Kahn's book [24], and the journal Cryptologia, can help identify cryptographic sites.

g) Investigate major libraries in the area. Some of these may have been pioneers in new methods of information access for their community. Academic staff in librarianship and information management may have good suggestions.

h) Search the timeline at the Computer History Museum [7]. Another useful website is Digibarn [10].

i) Ask your colleagues for suggestions. Some examples will indicate what is possible.

Sites in London include: the Science Museum (Babbage artefacts, reconstructed Difference Engine No. 1, and large computer section); several Charles Babbage sites, including his likely birthplace at Walworth, the site of the former Babbage home in Marylebone (with plaque), and his grave in Kensal Green cemetery; a plaque to Ada Lovelace at St James's Square; the 
house where Alan Turing was born, in Warrington Crescent; the City and Guilds Technical College site, in Leonard St, Finsbury, where the flip-flop was invented; the Royal Greenwich Observatory, which employed computers for just over 100 years from 1836; the Computer Museum at the University of Greenwich [26]; a plaque on the BT Centre in Newgate St to mark Marconi's wireless transmission there; an optical telegraph site in West Square, Kennington; and the grave of Thomas Bayes in Bunhill Fields (talk about Bayesian methods in machine learning).

New York City's Columbia University was the site of Herman Hollerith's work on tabulating machines, and of the first working model of the first personal computer, Simon, whose design had been outlined by Edmund Berkeley. Grace Hopper was born in New York City, studied at Vassar College, and worked there later. The famous chess match in which Deep Blue defeated world champion Garry Kasparov took place at the Equitable Center in 1997. Many human computers were employed in the New York Hydrographic Office at the Hudson Terminal Building [18]. ICT companies based in NYC include AOL, DoubleClick and Tumblr.

Chicago has the Museum of Science and Industry, and was the birthplace of the first online bulletin board system, CBBS, due to Ward Christensen and Randy Suess (1978). The key-driven mechanical calculators known as comptometers were developed there by Felt \& Tarrant. Elisha Gray, of the Western Union Telegraph Company in Chicago, was pipped by Bell in patenting the telephone in 1876. Teletype was introduced in Chicago by Charles Krumm and his son in 1907. The University of Chicago has a long history of computational work, going back to 1939 when it hosted the Cowles Commission for Economic Research, with its team of human computers, until 1955.

Paris has, for a start, its Musée de l'Informatique (from 2008), Musée des Arts et Métiers (from 1794) (including a calculator invented by Blaise Pascal), historic Paris Observatory, and the church Saint-Étienne-du-Mont where Pascal is buried.

Tokyo has the National Science Museum which includes Japan's first electronic computer, the FUJIC (designed by Okazaki Bunji, completed in 1956); Waseda University, where FUJIC was located for a time; the NTT History Center of Technologies; the Ridai Museum of Modern Science at the Tokyo University of Science; Nishamura Computers Collection (by appointment) at the Tokyo University of Agriculture Technology, and sites associated with companies including Fujitsu and Hemmi and other early computers such as MUSASINO-1.

In each of these cases, the lists we give are by no means comprehensive, and could doubtless be extended and improved by people with more local knowledge.

Smaller cities can support such tours as well. The city of Geelong is $75 \mathrm{~km}$ south-west of Melbourne, and has a population of about 180,000. Historically, it has been a centre for the wool industry and manufacturing. At first glance, one might not expect to find much ICT history there. But it has four important sites: an automatic punched-card weaving loom from 1910, still working, at the National Wool Museum; the Geelong Telegraph Station (1857), surmounted by a timeball; the first automatic telephone exchange in the southern hemisphere (1912); and the site of the first telephone call in Australia (1877). We ran group tours of the first three of these sites in May 2014 and April 2015.

Any list of sites needs to be considered for feasibility, to determine if there is a safe route enabling them to be visited in a reasonable time, and in some cases to determine arrangements for group access.

We have found that a tour group size in the low 20s works well. We are able to meet all participants over the course of the day, and make reasonable progress through the day. Our tour takes a full day and requires careful planning, allowing realistic times for transitions and moving around. Well-timed breaks are important. Some participants do not stay for the whole day. Seasonal weather is a factor in scheduling - in Melbourne, we avoid the hotter summer months. Our website [12] is designed to be usable for self-guided tours as well.

\section{CONCLUSIONS AND INVITATION}

We have described a new approach to interpretative heritage for ICT by combining the built environment with physical exhibits in formal museum displays in a guided tour to present the technological and cultural evolution of the field.

The development of the computer history tours of Melbourne has been a rewarding activity on many different levels, and has had a number of different outcomes. It has illustrated and reinforced technical concepts from the undergraduate curriculum, and demonstrated how fundamental and universal some of them are. It has raised awareness of the historical and social aspects of ICT, and given context for the technical concepts. It has given staff, students and alumni some extra value from their connection with the university. The program has stimulated research into topics for the tour as well as brought to light more sites of interest.

The tour has enabled us to meet many computer industry veterans with valuable recollections. It would be good to collect the memories and stories we come across in a more systematic way. We encourage participants to record their experiences and send the details, however there is scope for using technology to facilitate the systematic collection of this material.

While we have established a structured format for the tour, it is always evolving and more sites are being included as options. Future work on our tour could include a virtual online tour of some kind, or an app for a self-guided tour.

Although Melbourne is fortunate in its rich connections with the early days of computing, many other cities could support computer history tours too. We invite you to organise your own computer history tour and share your experiences.

\section{ACKNOWLEDGMENTS}

We are very grateful to the many people and organisations who have provided information and assisted with our visits to the various sites. Many of these are listed on our tour web page [12]. Special thanks are due to David Demant and Melbourne Museum for their work as curator and custodians of CSIRAC and their assistance with our visits there. We also acknowledge the invaluable work done by the CSIRAC Team, led by Peter Thorne, in ensuring its preservation, both at the time of its closure in 1964 and now as Research Associates with Melbourne Museum.

\section{REFERENCES}

[1] A Friend in Town, Silicon Valley -San Jose Sightseeing Tour, http://www.toursanfranciscobay.com/tours/siliconvalley-san-jose.html.

[2] Ainsworth, A.B., The Ferranti Sirius computer at Monash University, August 2008,

http://www.infotech.monash.edu.au/about/museum/papers/fir st-computer-at-monash-university-v7.pdf 
[3] Alegro Private Tours, http://alegroprivatetours.com/tours/silicon-valley-tours/

[4] Bletchley Park, http://www.bletchleypark.org.uk/

[5] Bureau of Meteorology, 50 Years of Computing in the Bureau of Meteorology, 2013.

[6] Cincotta, Katie, Top 11 things to do, Green Guide ('livewire' section), pp. 20-21, The Age (Melbourne), 1 December 2011, http:/www.theage.com.au/digital-life/top11-things-to-do-20111130-1o5mz.html

[7] Computer History Museum, Mountain View, Ca., http://www.computerhistory.org/

[8] Cooper, S. B. (ed.), Alan Turing Year, http://www.turingcentenary.eu/.

[9] De Mol, L., and Primiero, G. (chairs), International Conference on the History and Philosophy of Computing (HaPoC), Ghent University, Nov. 2011, http://www.computing-conference.ugent.be/

[10] Digibarn Computer Museum, http:/www.digibarn.com/

[11] Draper, G., Kessler, R., and Riesenfeld, R. A History of Computing Course with a Technical Focus. Proceedings of the 40th ACM Technical Symposium on Computer Science Education (SIGCSE 2009), ACM, 458-462.

[12] Farr, G., Ainsworth, B., Avram, C., and Sheard, J., Computing in Melbourne: A Historical Tour, http://www.csse.monash.edu.au/ gfarr/tour/.

[13] Farr, G., radio interview by Hilary Harper, 774 ABC Melbourne, 22 August 2009, 6:10am for $\sim 5$ mins, http://blogs.abc.net.au/victoria/2009/08/22/ (scroll down).

[14] Farrer, Gordon, Computer tour spins web of interest, The Age (Melbourne),14 May 2009, p24; online (without photo) at http://www.theage.com.au/national/computer-tour-spinsweb-of-interest-20090513-b3au.html?page $=-1$

[15] R. Freshwater, UK Telephone History, http://www.britishtelephones.com/histuk.htm

[16] Giangrandi, P. and Mirolo, C., Enhancing the general background of CS students through a computing history course. In: Proceedings of the Innovation and Technology in Computer Science Education Conference (ITiCSE), Madrid, Spain (2008), 301-305.

[17] Glinert, E. (organiser), private communication, 30 March 2014; URL for walks: http://www.newmanchesterwalks.com/event/alan-turing/

[18] Grier, D.A., When Computers Were Human, Princeton University Press, 2005.

[19] Hardy, G., Hall, S., Bates, A., and Kurzeme, I., VICNET and the web in the wider Victorian community, in: R S Debreceny and A E Ellis (eds.), AusWeb95 - Proceedings of the First Australian World Wide Web Conference, Norsearch Publishing, Lismore, NSW, 1995. http://ausweb.scu.edu.au/aw95/libraries/hardy/

[20] Heinz Nixdorf MuseumsForum, http://www.hnf.de/

[21] Impagliazzo, J. and Lee, J. A. N., Using computing history to enhance teaching. In J. Impagliazzo \& J. A. N. Lee (Eds.), History of Computing and Education, Kluwer Academic Publishers, Boston (2004), 165-175.

[22] Information Processing Society of Japan (IPSJ) Computer Museum, http://museum.ipsj.or.jp/
[23] Jones, R.V., Optical Telegraphy, http://people.seas.harvard.edu/ jones/cscie129/images/histor y/chappe.html

[24] Kahn, D., The Codebreakers, MacMillan, 1967, 1996.

[25] McCann, D., and Thorne, P., The Last of the First: CSIRAC: Australia's First Computer, Department of Computer Science and Software Engineering, University of Melbourne, 2000. http://www.cis.unimelb.edu.au/about/csirac/the-last-of-thefirst-csirac-ebook.pdf

[26] Mann, T., and Fedorec, A., Computer Museum, School of Computing and Mathematical Sciences, University of Greenwich, IEEE Annals of the History of Computing, 26 (1) (2004) 69-70.

[27] Marsh, A., Revolution: The first 2,000 years of computing. Technology and Culture 54 (3) (2013), 640-649.

[28] Monash Museum of Computing History, http://www.infotech.monash.edu.au/about/museum/

[29] Museum Victoria, CSIRAC: Australia's First Computer, http://museumvictoria.com.au/csirac/

[30] Nakano, H., Styles, M. G. and Draper, G. M., A call for champions: Why some 'History of Computing' courses are more successful than others. ACM Inroads, 4(1)(2013),26-28.

[31] Nexon Computer Museum, http://www.nexoncomputermuseum.org/

[32] Papadimitriou, C. H., MythematiCS: In Praise of Storytelling in the teaching of CS and Math, Proc. $8^{\text {th }}$ Ann. Conf. on ITiCSE, Inroads (SIGCSE Bulletin) 35 (3) (Sept. 2003), 7-9.

[33] Ryska, N. and Viehoff, J., The Heinz Nixdorf MuseumsForum, central venue for the "History of Computing". In: Making the History of Computing Relevant: IFIP WG 9.7 Internat. Conf., HC 2013 (2013), 47-52, Springer.

[34] Standage, T., The Victorian Internet, Walker \& Co., 1998.

[35] Tatnall, A. (ed.), History of Computing: Learning from the Past, IFIP WG 9.7 Internat. Conf., HC 2010, Springer, 2010.

[36] The National Museum of Computing, http://www.tnmoc.org/

[37] Tolerton, Jane, Look at how far computing has come, The Dominion Post (Wellington, NZ), 27 December 2008, pB3.

[38] Vincent, Jill, Shrine to University: A Geometry Journey along St. Kilda Road and Swanston Street, Math. Assoc. of Victoria, Brunswick, Vic., Australia, 1999. Later edition: http://www.mav.vic.edu.au/studact/im/IM_06.pdf.

[39] Virtual Museum of Computing, http://museums.wikia.com/wiki/VMoC

[40] Williams, M. R., The computer history museum. ACM SIGCSE Bulletin inroads, 35(4) (2003), 12-13.

[41] Zhang, C. and Howland, J. E., Brief and yet bountiful: The history of computing, why students need you? Journal of Computing Sciences in Colleges, 20(4) (2005), 308-314.

Picture credits:

Drawing of Melbourne Observatory (1863) and photo of the State Library of Victoria (1870-1889): State Library of Victoria (both out of copyright). Ferranti Sirius: Monash University Archives (IN6378), (C) Trevor Hicks (photographer). All other photos by Chris Avram (August 2008 or July 2010). 